\title{
STABILITY STUDY ON SCAFFOLDS WITH INCLINED SURFACES AND EXTENDED JACK BASES IN CONSTRUCTION
}

\author{
Jui-Lin Peng ${ }^{1,}$, , Shu-Hong Wang ${ }^{2}$, Chung-Sheng Wang ${ }^{3}$ and Judy P. Yang ${ }^{4}$ \\ Department of Civil and Construction Engineering, National Yunlin University of Science and Technology, Yunlin, Taiwan, China. \\ ${ }^{2}$ School of Resource and Civil Engineering, Northeastern University, Shenyang, China. \\ ${ }^{3}$ Graduate School of Engineering Science and Technology, National Yunlin University of Science and Technology, Taiwan, China. \\ ${ }^{4}$ Department of Civil Engineering, National Chiao Tung University, Hsinchu, Taiwan, China. \\ *(Corresponding author: E-mail: pengjl@yuntech.edu.tw)
}

\section{A B S T R A C T}

A scaffolding system is a temporary structure that is commonly adopted on construction sites. As steel scaffolds are modular members manufactured with fixed dimensions, the total height of a scaffolding system seldom fits the headroom of a building when scaffolds are set up in multiple stories. This results in a difference in elevation, i.e. gap, between the top of the scaffolding system and the ceiling slab. In addition, scaffold configurations may need to be adjusted if the interior of a building has inclined planes on the ceiling slab or stairs on the ground. This study shows that the gap between the scaffold and the ceiling slab can be eliminated by altering the lengths of adjustable base jacks or adjustable U-head jacks. When the ceiling slab is inclined, it is suggested that a combined system of scaffolds with wooden shores of different lengths should be installed in the out-of-plane direction of the scaffold unit. This system can also be used when the ceiling slab is inclined and the ground has a difference in elevation (e.g., stairs) in a building. By using the second-order elastic analysis with semirigid joints, the load-bearing capacity and failure model are found to be very close to those obtained in the loading tests using various scaffold configurations. In the loading tests for reused scaffolds, the lower bound of the load-bearing capacity of the scaffolding systems can be obtained by applying a subsequent load on the scaffolding systems, which are commonly adopted on the construction sites. The strength reduction factor $(\phi)$ of these scaffolding systems installed by reused scaffolds can be obtained by calculating the mean value and standard deviation, which can serve as a reference for the strength design of scaffolding systems with different safety requirements.
ART I CLE H IS T O RY

$\begin{array}{ll}\text { Received: } & \text { 8 March } 2020 \\ \text { Revised: } & \text { 8 March 2020 } \\ \text { Accepted: } & \text { 10 September 2020 }\end{array}$

K E Y W O R D S

Buckling;

Critical load;

Loading test;

Scaffold;

Wooden shore

\section{Introduction}

In construction, scaffolding systems are commonly known as temporary structures, in which all steel scaffolds are modular members with fixed dimensions. When the scaffolds are installed in multiple stories, the total height of the scaffolding system often does not fit the headroom of the building. This leads to a gap between the top of the scaffolding system and the bottom of the ceiling slab. To eliminate such a gap, a combined structure of scaffolds is constructed by inserting other shores such as tubular steel adjustable shores or wooden shores, which is called the combined system of scaffolds with shores in this study. On the other hand, the gap between the top of the scaffolding system and the ceiling slab can also be closed by directly extending the length of adjustable U-head jacks on the top or adjustable base jacks at the bottom of the scaffolding system to make the overall height of the scaffolding system fit the headroom of the building. However, the stability behavior of this configuration has seldom been discussed so far. Furthermore, when the ceiling slab of the building is inclined, the stability behavior of the combined system of scaffolds with shores is different from that of the same system when the ceiling slab is not inclined. The situation is similar to the ground having an elevation difference such as stairs, thereby leading to an uneven bottom surface. The aforementioned situations might affect the load-bearing capacity of the combined system of scaffolds with shores, and the potential collapse risk of the combined system of scaffolds with shores might be increased. Fig. 1 shows the collapse of falseworks in construction of an iron and steel company in Central Taiwan; this accident caused one death and several injuries.

By treating scaffolds as temporary supports, Yu et al. investigated the loadbearing capacity of modular steel scaffolds in the laboratory; they also conducted numerical analyses to compare with the results obtained in the loading tests and to confirm the relationship between story numbers and load capacity in modular steel scaffolds used in Hong Kong [1,2]. Pieńko and Błazik-Borowa investigated the nodes of scaffolds based on numerical analysis, in which the load-bearing capacitiy of the nodes of scaffolds were analyzed by considering joint interaction of scaffolds with the use of nonlinear material [3]. Jia et al. investigated the slipping and rotational stiffnesses in the right-angle coupler connections of scaffolds based on experimental tests, and they focused on some specific issues, such as bolt-tightening torques, different coupler combinations, loading patterns, and conditions of new and old components [4]. Zhao et al. investigated the influence of member imperfection and joint stiffness on the load-bearing capacity of modular scaffolds by using the finite element method, where the influences of the splice joint stiffness and the screw jack stiffness on the load-bearing capacity of modular scaffolds were discussed [5]

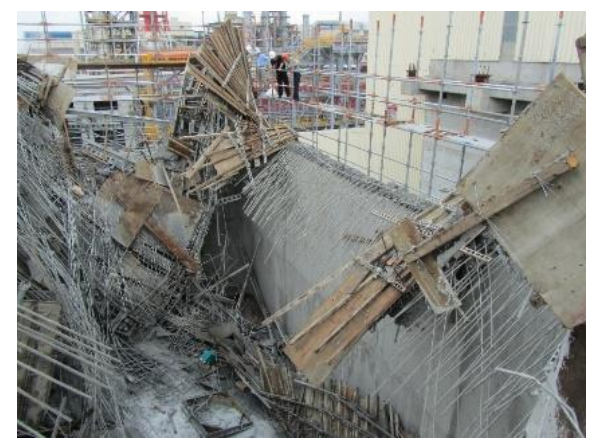

Fig. 1 Scene of the collapse of falsework in construction of an iron \& steel company in Central Taiwan

Upon treating a scaffolding structural system as a temporary support, Peng et al. investigated the ultimate loads of various single-row scaffolding structural systems [6]. When multi-bay setups of scaffolds were considered, the ultimate loads of the two-story scaffolds increased with the number of bays. Peng et al. further investigated the ultimate loads and failure models of an outdoor fullscale heavy-duty scaffolding structural system to verify the mechanical behavior of scaffolds [7]. In this study, it is revealed that the ultimate load and failure model of the isolated three-story heavy-duty scaffold system were similar to those of the two-story heavy-duty scaffold system. Liu et al. investigated the mechanical behavior of tube and coupler scaffolds with $\mathrm{X}$ bracings [8], in which two full-scale scaffolding structural systems with $\mathrm{X}$ bracings were tested in the laboratory, and a finite element analysis was conducted to compare the discrepancies between the analyzed and experimental results.

Among other configurations of scaffolding, Sevim et al. investigated the structural behavior of tie-bar numbers on the suspended scaffolding systems in the laboratory. In this study, they tested fifteen suspended scaffolding systems and obtained the load-displacement curves; particularly, the optimal suspended scaffolding system in terms of safety and cost was determined [9].

Concerning the reliability and probability of scaffold failure, Zhang et al. investigated the ultimate strength uncertainty of multi-story scaffolds through the use of an appropriate statistical framework with the second-order inelastic analysis $[10,11]$. The reliability-based analyses were performed on the basis of a data survey and a probabilistic model of the load-bearing capacity of scaffolds 


\section{during grouting.}

From the aforementioned studies, it is shown that most researchers have focused their attention on the load-bearing capacities and failure models of various scaffolds, such as frame-type scaffolds, and tube and coupler steel scaffolds. In addition the vertical load of fresh concrete is considered as the major external load applied on a scaffolding system. Nevertheless, these studies have seldom considered the load-bearing capacities and failure models of the combined system of scaffolds with shores. Furthermore, these studies have seldom explored the boundary conditions of an inclined ceiling slab or uneven ground, and the issue of adjustable U-head jacks and adjustable base jacks in scaffold systems. The present study focuses on these issues for practical application in construction sites.

\section{Research significance}

To understand the critical load and failure model of various scaffold configurations, this study explores the stability behavior of a scaffolding system by considering the following conditions: the inclined ceiling slab, an elevation difference on the ground (e.g. stairs), and the extension of adjustable U-head jacks on the top and adjustable base jacks at the bottom of the system. Furthermore, two subsequent loads are applied to the scaffolding system during the loading tests in order to understand the lower bound of the load-bearing capacity of scaffolding systems commonly used in construction.

In the test of two subsequent loads, the critical load of the scaffolding system is obtained when the first load is applied. After unloading the first load, the scaffolding system returns to its original condition. Then, the second load is applied to simulate the worst case of the load-bearing capacity of the scaffolding system. The ratio of the load-bearing capacity of the scaffolding system under the second load to that under the first load can be considered as the strength reduction factor of the scaffolding system, which may serve as a reference for strength design of the scaffolding system in the future. This study includes the following highlights:

- To determine the effect of extended adjustable U-head jacks on the top and adjustable base jacks at the bottom of the system on the loadbearing capacity of the scaffolding system;

- To determine the effect of the top inclined plane on the load-bearing capacity of the combined system of scaffolds with shores;

- To determine the effect of the top inclined plane and uneven ground on the load-bearing capacity of the combined system of scaffolds with shores; and

- To determine the lower bound of the load-bearing capacity of "scaffolding system" and "combined system of scaffolds with shores".

\section{Dimensions and material properties}

This study adopts door-type steel scaffolds to conduct tests and analysis. The overall configuration of the door-type scaffolding structure is shown in Fig. 2. Additionally, six specimens are randomly selected from door-type steel scaffolds in the laboratory to find the mechanical properties of scaffolds.

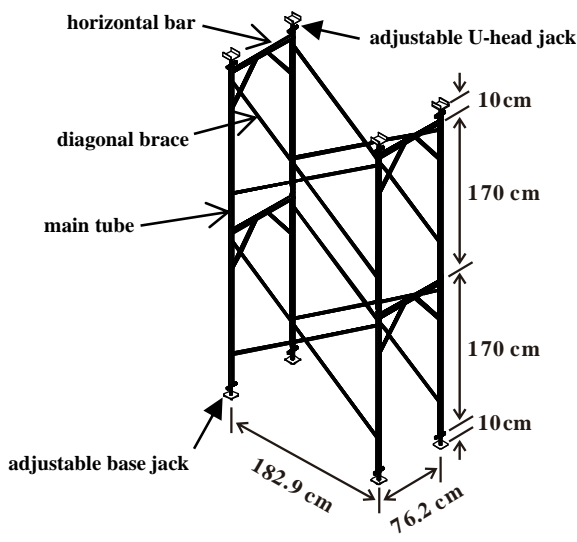

Fig. 2 Dimensions and schematic diagram of the two-story scaffolding system of basic configuration

The mean dimensions of the structural members are given as follows: For the door-type steel scaffolds, main tube: mean outer diameter $\Phi=42.4 \mathrm{~mm}$, mean thickness $t=2.10 \mathrm{~mm}$; horizontal bar: mean outer diameter $\Phi=42.2 \mathrm{~mm}$, mean thickness $t=2.08 \mathrm{~mm}$; diagonal brace: mean outer diameter $\Phi=26.6 \mathrm{~mm}$, mean thickness $t=1.66 \mathrm{~mm}$; cross brace: mean outer diameter $\Phi=21.2 \mathrm{~mm}$, mean thickness $t=1.46 \mathrm{~mm}$; adjustable base jack and adjustable U-head jack: mean outer diameter $\Phi=24.9 \mathrm{~mm}$. The mean square area of the wooden shores is obtained by measuring the cross sections of the wooden shores, and it is calculated as $30.25 \mathrm{~cm}^{2}$. The cross-sectional moment of inertia is $I_{y}=I_{z}=$ $76.2552 \mathrm{~cm}^{4}$

Additionally, three sets of door-type steel scaffolds are selected for the material test. The following data are obtained from the material tests: mean elastic modulus $E=196 \mathrm{kN} / \mathrm{mm}^{2}$, mean yielding stress $F_{y}$ $=0.36 \mathrm{kN} / \mathrm{mm}^{2}$, mean ultimate strength $F_{u}=4.47 \mathrm{kN} / \mathrm{mm}^{2}$. For the wooden shores, the mean elastic modulus $E=1245 \mathrm{kN} / \mathrm{mm}^{2}$, mean yielding stress $F_{y}=0.046 \mathrm{kN} / \mathrm{mm}^{2}$.

\section{Numerical analysis}

In this study, the "second-order elastic analysis with semi-rigid joints" is adopted for the numerical analysis of the scaffolding systems. To simulate the initial imperfection of the overall scaffolding systems in the analysis, the notional lateral forces are applied to vertical members on mutually perpendicular planes. NIDA, a software package developed by Professor S.L. Chan of the Hong Kong Polytechnic University, was adopted for analysis in this study $[12,13,14,15]$. In the second-order elastic analysis, both the P- $\Delta$ effect and $\mathrm{P}-\delta$ effect of the structural members are considered.

\section{Test planning}

\subsection{Scaffolding system with adjustable base jacks and adjustable U-head jacks of different lengths}

\subsubsection{Basic configuration of a scaffolding system}

A scaffolding system with a basic two-story configuration is adopted in the tests. The adjustable base jack and adjustable U-head jack used in the scaffolding system for the tests are both $10 \mathrm{~cm}$ in length. The dimensions of the two-story scaffolding system are shown in Fig. 2. The critical load and failure model of the two-story scaffolding system obtained in the tests are compared with the test results of other scaffold configurations adopted in this study.

\subsubsection{Scaffolding system with extended adjustable U-head jacks}

To fit the total height of the scaffolding system with the headroom of the building, workers may adjust the length of the adjustable U-head jacks on the top of the scaffolds. In the experiment, the adjustable U-head jacks of the scaffolding system are extended to a full length of $65 \mathrm{~cm}$, and the scaffold configuration is shown in Fig. 3(A)

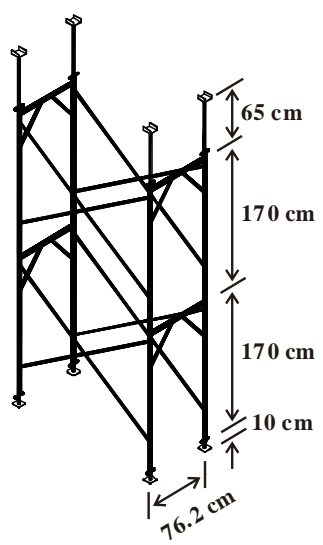

(A) Extended U-head jacks

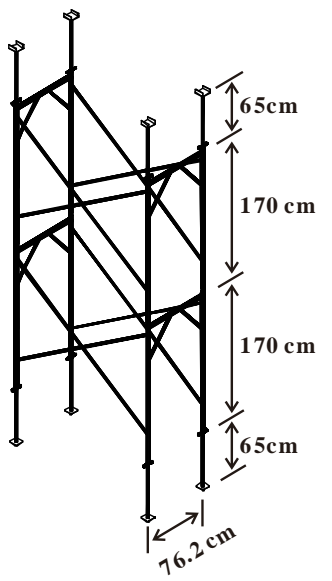

(B) Extended U-head jacks and base jacks
Fig. 3 Schematic diagram of the scaffolding system with extended adjustable U-head jacks and adjustable base jacks

\subsubsection{Scaffolding system with extended adjustable U-head jacks and adjustable} base jacks

For the case that the total height of the scaffolding system with extended U-head jacks does not fit the headroom of the building, workers may adjust the length of the adjustable base jacks as well. In the experiment, both the adjustable U-head jacks and adjustable base jacks are extended to a full length of $65 \mathrm{~cm}$. The corresponding configuration is shown in Fig. 3(B).

\subsection{Two-story combined system of scaffolds with wooden shores}

5.2.1. Wooden shores of the same length $(\alpha=1.0)$ 
To solve the problem of insufficient length of scaffolds when fitting the headroom of a building, it is advisable to consider setting up other shores on the top of scaffolds to close the gap between the scaffold and the ceiling slab. For the sake of convenience in the loading tests and numerical analyses, wooden shores are served as "other shores" in this study. Fig. 4 shows the setup of the combined system of scaffolds with wooden shores of the same length. To clearly explain the length of the wooden shores in this study, the ratio of the length of the wooden shores to that of the scaffolds $(1.7 \mathrm{~m}$ ) is defined as $\alpha$ (namely, $\alpha$ is the wooden shore length divided by1.7 $\mathrm{m}$ ).

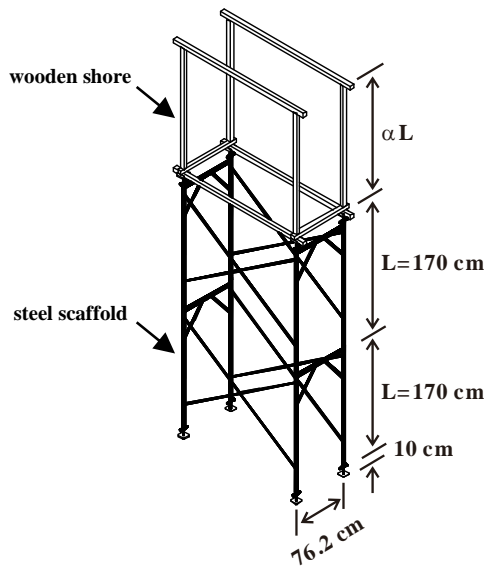

Fig. 4 Schematic diagram of the two-story combined system of scaffolds with wooden shores

The length of the wooden shores adopted in the experiment is $1.7 \mathrm{~m}$, which results in $\alpha=1(=1.7 \mathrm{~m} / 1.7 \mathrm{~m})$. The results of the experiment can be compared with those obtained in the experiment using a two-story scaffolding system and a combined system of scaffolds with wooden shores underneath an inclined ceiling slab.

\subsubsection{Wooden shores of the same length $(\alpha=0.382)$}

For the case that the gap between the scaffolds and the ceiling slab is not very large, shorter wooden shores may be used to adjust the total height of the scaffolding system. The corresponding configuration is shown in Fig. 4. To clearly compare the test results of the scaffolding system with the extended adjustable U-head jacks, the length of the wooden shores on the top of the scaffolds is set as $65 \mathrm{~cm}$, which is the same as the length of the extended adjustable U-head jacks. These results can be used to compare the performance of the scaffolding system with top wooden shores with that of the system extended by adjustable U-head jacks.

\subsubsection{Inclined ceiling slab}

To explore the stability behavior of the combined system of scaffolds with wooden shores underneath an inclined ceiling slab, the configurations shown in Fig. 5 are adopted in the experminet. Since there are strong axes and weak axes in a scaffolding structure, for the sake of convenience, this study defines the $x y$ plane in the in-plane direction of a scaffold unit and the $y z$-plane in the out-ofplane direction of a scaffold unit.
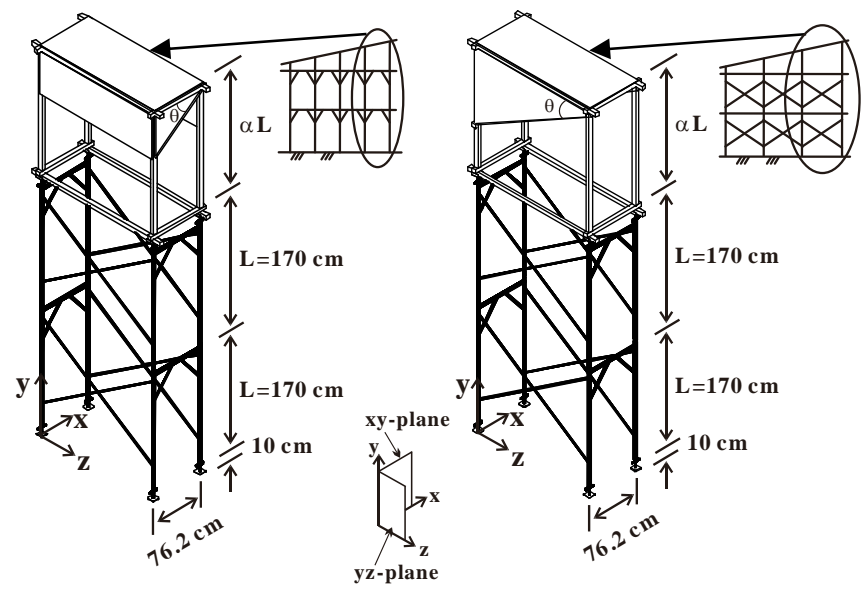

(A) Inclined plane in the in-plane direction (xy-plane)

(B) Inclined plane in the out-of-plane direction (yz-plane)

Fig. 5 Schematic diagram of the combined system of scaffolds with wooden shores with an inclined plane $\theta=30^{\circ}$ and wooden shore length $\alpha=1$
As shown in Fig. 5(A), the inclined plane of the ceiling slab is on the xyplane; that is, it inclines in the in-plane direction. As shown in Fig. 5(B), the inclined plane of the ceiling slab is on the yz-plane; that is, it inclines in the outof-plane direction.

As shown in Fig. 5(A) and Fig. 5(B), the longest wooden shore on the upper layer of the scaffolding structure is $1.7 \mathrm{~m}(\alpha=1)$. The inclination angle of the ceiling slab $(\theta)$ is $30^{\circ}$ downward. In the in-plane direction, the shorter wooden shores are $126 \mathrm{~cm}$ long $\left(=170-76.2 \times \tan 30^{\circ}\right)$; in the out-of-plane direction, the shorter wooden shores are $64.4 \mathrm{~cm}$ long $\left(=170-182.9 \times \tan 30^{\circ}\right)$. The test results can be compared with the cases without inclined ceiling slabs. They can also be used to review the stability behavior of scaffolding systems with ceiling slabs inclined in two different directions.

\subsubsection{Inclined ceiling slab and uneven ground surface}

Due to the interior configuration of buildings, it is common to see an inclined ceiling slab on the top and an uneven ground surface at the bottom. The stability behavior of the combined system of scaffolds with wooden shores under these conditions is explored. The configurations of the combined system of scaffolds with wooden shores under both out-of-plane and in-plane inclined directions are also adopted in this study (as shown in Fig. 6).

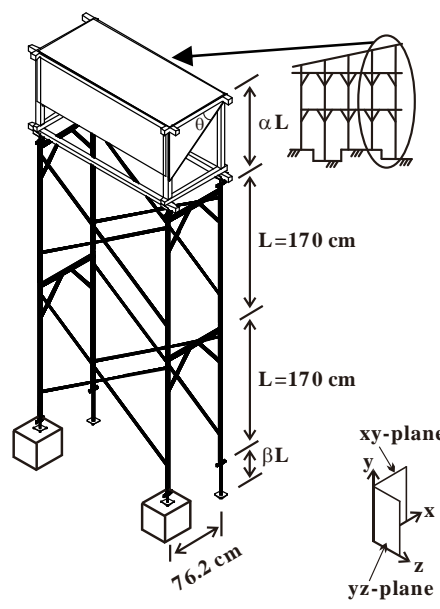

(A) Inclined plane in in-plane direction $\left(\theta=30^{\circ}, \alpha=0.5, \beta=0.15\right)$

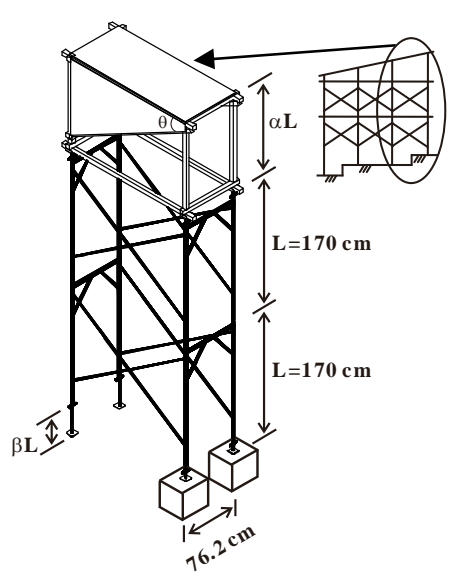

(B) Inclined plane in out-of-plane direction $\left(\theta=30^{\circ}, \alpha=0.7, \beta=0.15\right)$
Fig. 6 Schematic diagram of the combined system of scaffolds with wooden shores with an inclined plane $\theta=30^{\circ}$ and wooden shore length $\alpha=0.5 \& 0.7$

Fig. 6(A) shows the combined system of scaffolds with wooden shores under conditions of uneven top and bottom surfaces in the in-plane direction. As shown in Fig. 6(A), in the two-story combined system of scaffolds with wooden shores, the longer wooden shores are $85 \mathrm{~cm}(\alpha=0.5)$, the inclination angle of the ceiling slab is $30^{\circ}\left(\theta=30^{\circ}\right)$, the shorter wooden shores are $41 \mathrm{~cm}$ $\left(=85-76.2 \times \tan 30^{\circ}\right)$, and the length of the base jack at one side is $25.5 \mathrm{~cm}(=$ $0.15 \times 170, \beta=0.15)$.

Similarly, Fig. 6(B) shows the combined system of scaffolds with wooden shores under conditions of uneven top and bottom surfaces in the out-of-plane direction. As shown in Fig. 6(B), in the two-story combined system of scaffolds with wooden shores, the longer wooden shores are $119 \mathrm{~cm}(\alpha=0.7)$, the inclination angle of the ceiling slab is $30^{\circ}\left(\theta=30^{\circ}\right)$, the shorter wooden shores are $13.4 \mathrm{~cm}\left(=119-182.9 \times \tan 30^{\circ}\right)$, and the length of the base jack at one side is $25.5 \mathrm{~cm}(=0.15 \times 170, \beta=0.15)$.

\section{Discussions on results of tests and analyses}

\subsection{Scaffolding system with adjustable base jacks and U-head jacks of different lengths}

\subsubsection{Basic configuration of scaffolding system}

Two sets of two-story scaffolding systems with basic configurations were used in the experiment, and the test results are shown in Table 1. As shown in Table 1, the mean critical load of the two-story scaffolding system is 107.383 $\mathrm{kN}$ and the corresponding mean vertical deformation is $5.932 \mathrm{~mm}$. The results of the loading tests are shown in Fig. 7. As shown in Fig. 7, the structural deformation occurs in the front row of the scaffolding system, while the buckling mainly occurs in the in-plane direction. The load vs. vertical displacement curve of the two-story scaffolding system with a basic configuration under the loading test is shown in Fig. 8. Since the trend of the load vs. vertical displacement curves obtained from other tests in this study is similar to these obtained herein, the results from other tests are not included due to limited space. 
Table 1

Test results of the scaffolding system with adjustable base jacks and adjustable U-head jacks of different lengths

\begin{tabular}{|c|c|c|c|c|c|c|c|c|c|c|}
\hline \multirow{2}{*}{ Item } & \multirow{2}{*}{ Type } & \multirow{2}{*}{$\begin{array}{l}\text { Fig- } \\
\text { ure }\end{array}$} & \multirow{2}{*}{$\begin{array}{l}\text { Configu- } \\
\text { ration }\end{array}$} & \multirow{2}{*}{ Numbering } & \multirow{2}{*}{ Unit } & \multicolumn{3}{|c|}{ (a).Test value } & \multirow{2}{*}{$\begin{array}{l}\text { (b). Analy- } \\
\text { sis }(\mathrm{kN})\end{array}$} & \multirow{2}{*}{$\begin{array}{l}((a-b) / a) \\
\times 100 \%\end{array}$} \\
\hline & & & & & & Group A & Group B & Mean & & \\
\hline \multirow{2}{*}{1} & \multirow{2}{*}{$\begin{array}{l}\text { 2-story scaffod Sys- } \\
\text { tem }\end{array}$} & & \multirow{2}{*}{$\begin{array}{l}\text { Flat slab and } \\
\text { ground }\end{array}$} & $\begin{array}{c}\text { BN2D } \\
\text { (BN2DT) }\end{array}$ & $\mathrm{kN}$ & $\begin{array}{l}108.795 \\
(96.380) \\
\end{array}$ & $\begin{array}{l}105.971 \\
(90.898) \\
\end{array}$ & $\begin{array}{l}107.383 \\
(93.644) \\
\end{array}$ & \multirow{2}{*}{107.19} & \multirow{2}{*}{$0.2 \%$} \\
\hline & & & & Deformation & $\mathrm{mm}$ & $\begin{array}{l}5.189 \\
(4.275)\end{array}$ & $\begin{array}{c}6.675 \\
(4.791)\end{array}$ & $\begin{array}{c}5.932 \\
(4.533)\end{array}$ & & \\
\hline \multirow[b]{2}{*}{2} & \multirow{4}{*}{$\begin{array}{c}\text { U-head jacks/ base } \\
\text { jacks of different } \\
\text { lengths }\end{array}$} & & \multirow{2}{*}{$\begin{array}{l}\text { Ext. U-head } \\
\text { jacks }\end{array}$} & $\begin{array}{c}\mathrm{UJ}_{\mathrm{J}} 65 \mathrm{D} \\
\left(\mathrm{U}_{\mathrm{J}} 65 \mathrm{DT}\right) \\
\end{array}$ & $\mathrm{kN}$ & $\begin{array}{l}111.786 \\
(79.336) \\
\end{array}$ & $\begin{array}{l}108.020 \\
(83.033) \\
\end{array}$ & $\begin{array}{l}109.903 \\
(81.185) \\
\end{array}$ & \multirow[b]{2}{*}{106.80} & \multirow[b]{2}{*}{$2.8 \%$} \\
\hline & & & & Deformation & $\mathrm{mm}$ & $\begin{array}{l}8.096 \\
(6.669)\end{array}$ & $\begin{array}{l}8.300 \\
(7.094)\end{array}$ & $\begin{array}{l}8.198 \\
(6.882)\end{array}$ & & \\
\hline \multirow[b]{2}{*}{3} & & & \multirow[b]{2}{*}{$\begin{array}{l}\text { Ext. U-head and } \\
\text { base jacks }\end{array}$} & $\begin{array}{c}\text { UJ65J65D } \\
\text { (Us65J65DT) }\end{array}$ & $\mathrm{kN}$ & $\begin{array}{c}81.346 \\
(65.381) \\
\end{array}$ & $\begin{array}{c}75.011 \\
(54.211) \\
\end{array}$ & $\begin{array}{c}78.179 \\
(59.791) \\
\end{array}$ & \multirow[b]{2}{*}{74.49} & \multirow[b]{2}{*}{$4.7 \%$} \\
\hline & & & & Deformation & $\mathrm{mm}$ & $\begin{array}{c}7.607 \\
(5.234)\end{array}$ & $\begin{array}{l}7.150 \\
(6.203)\end{array}$ & $\begin{array}{c}7.379 \\
(5.719)\end{array}$ & & \\
\hline
\end{tabular}

Notes:

1. Data in parentheses denote test values of the second load after the scaffolding system is unloaded and then reloaded.

2. All test configurations include the adjustable base jacks and U-head jacks if not otherwise specified.

3. In the numerical analysis of this study, the joint stiffness of the steel scaffolds is $2500 \mathrm{kN}-\mathrm{cm} / \mathrm{rad}$; that of the adjustable base and U-head jacks is $450 \mathrm{kN}$-cm/rad.

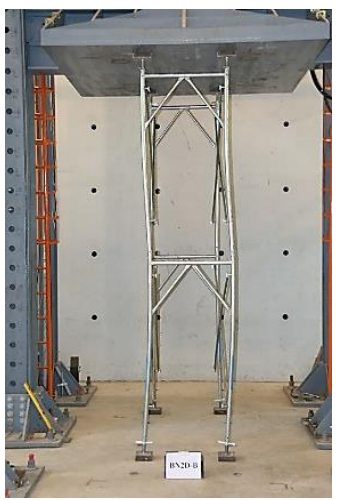

Fig. 7 Deformation of the two-story scaffolding system with basic configuration after loading

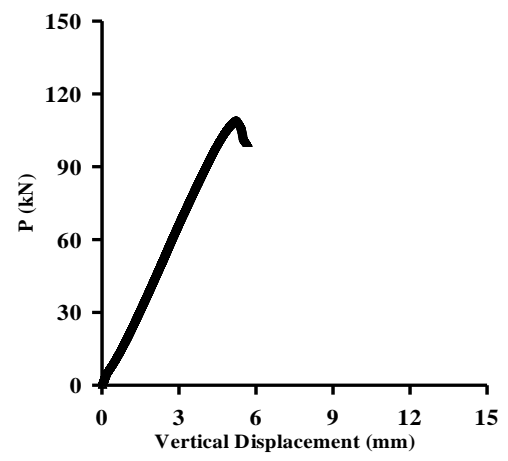

Fig. 8 Load vs. displacement curve of the two-story scaffolding system with basic configuration (BN2D-A) after loading

After finishing this test, the scaffolding system was unloaded and rearranged to its original condition to prepare for the second load. The second load simulates the worst case of the load-bearing capacity of the reused scaffolding system on construction sites. As shown in Table 1, the mean critical load of the two-story scaffolding system under a second load is $93.644 \mathrm{kN}$ and the corresponding mean vertical deformation is $4.533 \mathrm{~mm}$. Again, when the scaffolding system fails, the deformation mainly occurs in the front row and the buckling mainly occurs in the in-plane direction.

The second-order elastic analysis with semi-rigid joints was adopted in this study. With reference to previous studies of second-order elastic analyses on the joint stiffness of scaffolds, the stiffness values of each joint in the scaffolding system can be obtained and are shown in Fig. 9(A). As shown in Fig. 9(A), it is observed that the joint stiffness $\left(k_{S I}\right)$ between vertical tubes of the scaffolding system is $2500 \mathrm{kN}-\mathrm{cm} / \mathrm{rad}$, and the joint stiffness of base jacks and U-head jacks $\left(k_{s 2}\right)$ is $450 \mathrm{kN}-\mathrm{cm} / \mathrm{rad}$. After analysis, the critical load of the scaffolding system was obtained as $107.19 \mathrm{kN}$.

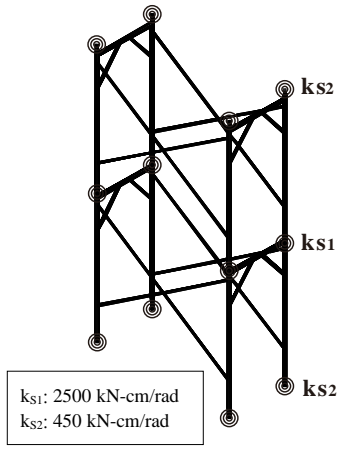

(A) scaffolding system

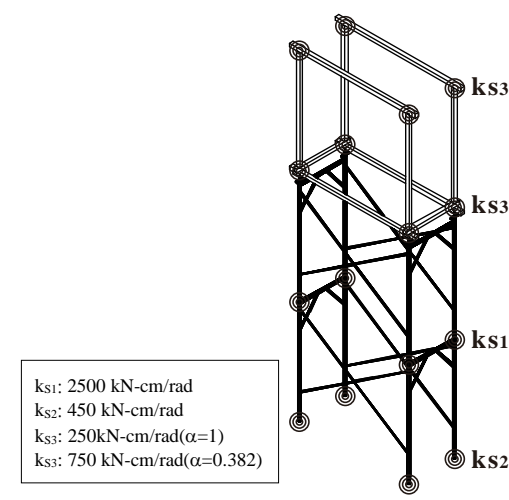

(B) combined system of scaffolds with wooden shores
Fig. 9 Schematic diagram of the spiral spring stiffness of various joints and their positions in the scaffolding system and combined system of scaffolds with wooden shores

Fig. 10(A) shows the deformation of the scaffolding system of basic configuration after loading, which is similar to that of the two-story scaffolding system as shwon in Fig. 7. Fig. 10(B) shows the relationship between the total vertical load and horizontal displacement on point A of the scaffolding system. Due to limited space, if similar setups of the scaffolding systems give similar analysis results to this case, they will be omitted from now on.

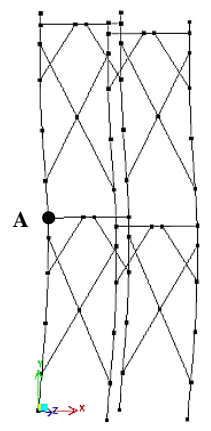

(A) Deformation after loading

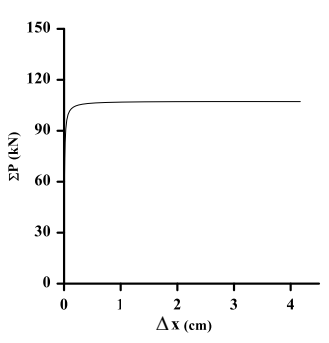

(B) Load vs. horizontal displacement diagram
Fig. 10 Results of the second-order elastic analysis with semi-rigid joints on the two-story scaffolding system with basic configuration

As shown in Table 1, the analysis value, $107.19 \mathrm{kN}$, is very close to the test value, $107.383 \mathrm{kN}$. The deviation of both values is around $0.2 \%$. The joint stiffnesses of the steel tubes, adjustable base jacks, and adjustable U-head jacks adopted in other scaffold configurations in this study are the same as those used in this scaffold configuration.

\subsubsection{Scaffolding system with extended adjustable U-head jacks}

Two sets of scaffolding systems were adopted in the experiment. The test results show that the mean critical load of these scaffolding systems is 109.903 $\mathrm{kN}$, which is also shown in Table 1. Fig. 11 shows that the deformation of the scaffolding system after loading occurs in the in-plane direction of the back-row 
scaffolds. After unloading, the scaffolding system was rearranged to prepare for the second load. The mean critical load of the second loading tests was 81.185 $\mathrm{kN}$. The deformation of the scaffolding system under the second load also occurred in the back row of the scaffolding system.

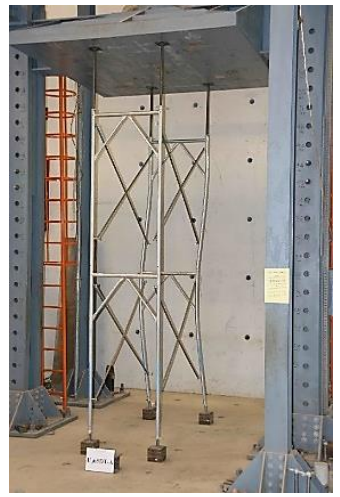

Fig. 11 Deformation of the scaffolding system with extended adjustable U-head jacks after loading

As shown in Fig. 11, although the adjustable U-head jacks are extended to $65 \mathrm{~cm}$, when the scaffolding structure fails, the deformation does not occur on the extended U-head jacks, but in the in-plane direction of the back-row scaffolds. As shown in Table 1, when the length of the U-head jacks is $10 \mathrm{~cm}$, the critical load of the scaffolding system is $107.383 \mathrm{kN}$; when the length of the U-head jacks is $65 \mathrm{~cm}$, the critical load of the scaffolding system is $109.903 \mathrm{kN}$. The failure of the scaffolding system is due to buckling in both cases, indicating that the effect of the extended $65 \mathrm{~cm} \mathrm{U}$-head jacks on the critical load is not obvious.

In the numerical analysis, the stiffnesses of the various joints of previous scaffolding systems were adopted. From the second-order elastic analysis, the critical load was obtained as $106.80 \mathrm{kN}$ (as shown in Table 1). Fig. 12(A) shows the deformation of the scaffolding system with extended adjustable U-head jacks after loading, which is similar to that of the two-story scaffolding system shown in Fig. 11. Fig. 12(B) shows the relationship between the total vertical load and the horizontal displacement at point A of the scaffolding system. The analysis value, $106.80 \mathrm{kN}$, is close to the test value, $109.903 \mathrm{kN}$. The deviation of both values is around $2.8 \%$. The deformation and the critical load of the scaffolding system are similar to the failure model of the scaffolding systems being tested.

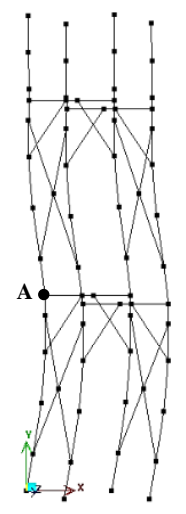

(A) Deformation after loading

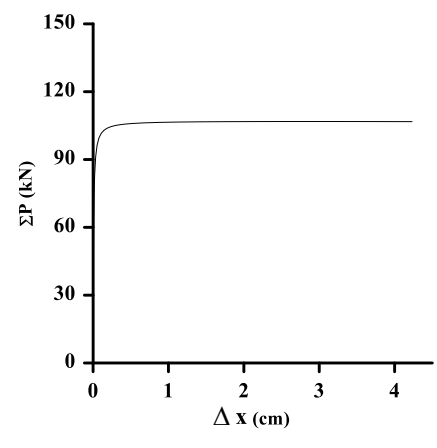

(B) Load vs. horizontal displacement diagram
Fig. 12 Results of the second-order elastic analysis with semi-rigid joints on the scaffolding system with extended adjustable U-head jacks

6.1.3. Scaffolding system with extended adjustable U-head jacks and base jacks Two tests were conducted, in which both the adjustable U-head jacks and base jacks were extended to $65 \mathrm{~cm}$. The test results in Table 1 show that the mean critical load of the scaffolding system is $78.179 \mathrm{kN}$. Fig. 13 shows the deformation of the scaffolding system, and Fig. 14 shows the details of the deformation of the adjustable U-head jacks after loading. The load-bearing capacity of the scaffolding system is lower than those of the previous two scaffold configurations. Additionally, the deformation of the scaffolding system after loading is different from those of the previous two scaffold configurations, mainly because the structural failure of the scaffolding system occurs on the extended adjustable U-head jacks and base jacks, instead of on the scaffolding system itself.

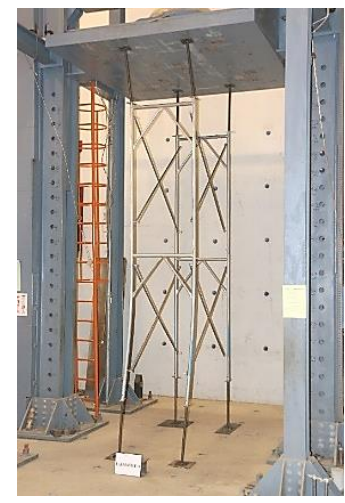

Fig. 13 Deformation of the scaffolding system with both extended adjustable U-head jacks and base jacks after loading

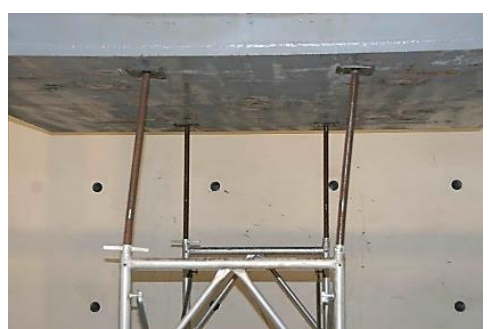

Fig. 14 Deformation of the adjustable U-head jacks of the scaffolding system with both extended adjustable U-head jacks and base jacks after loading

Similarly, after unloading, the scaffolding systems were rearranged to prepare for the second loading test. After testing, the mean critical load was found to be $59.791 \mathrm{kN}$, and the deformation of the scaffolding systems at failure was the same as that after the first load.

As shown in Fig. 15, the critical load, $78.179 \mathrm{kN}$, of the scaffolding system with both extended adjustable U-head jacks and base jacks is around 0.73 (= 78.179/107.383) times that of the scaffolding system with a basic configuration, $107.383 \mathrm{kN}$. This indicates that when the adjustable U-head jacks and base jacks are both extended to $65 \mathrm{~cm}$, the load-bearing capacity of the scaffolding system is not significantly affected. It retains around $70 \%$ of its original load-bearing capacity.

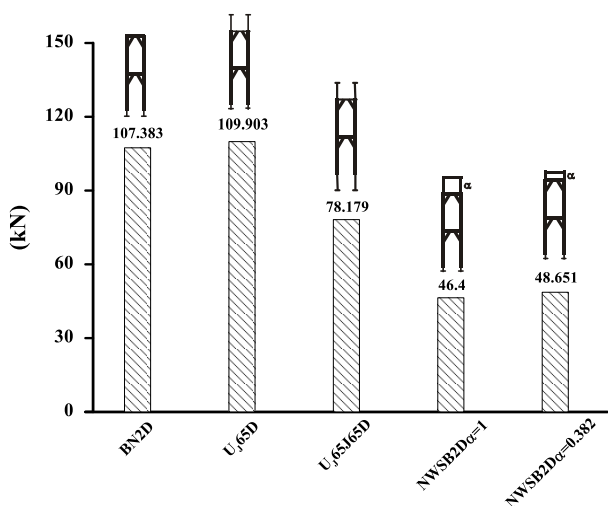

Fig. 15 Comparison of the critical loads of different scaffolding systems with extended adjustable U-head jacks and base jacks and top wooden shores 
Table 2

Test results of the combined system of scaffolds with wooden shores of different lengths

\begin{tabular}{|c|c|c|c|c|c|c|c|c|c|c|}
\hline \multirow{2}{*}{ Item } & \multirow{2}{*}{ Type } & \multirow{2}{*}{$\begin{array}{l}\text { Fig- } \\
\text { ure }\end{array}$} & \multirow{2}{*}{$\begin{array}{l}\text { Configu- } \\
\text { ration }\end{array}$} & \multirow{2}{*}{ Numbering } & \multirow{2}{*}{ Unit } & \multicolumn{3}{|c|}{ (a).Test value } & \multirow{2}{*}{$\begin{array}{l}\text { (b).Analy- } \\
\text { sis (kN) }\end{array}$} & \multirow{2}{*}{$\begin{array}{l}((a-b) / a) \\
\times 100 \%\end{array}$} \\
\hline & & & & & & Group A & Group B & Mean & & \\
\hline \multirow[b]{2}{*}{1} & \multirow{4}{*}{$\begin{array}{l}2 \text {-story com- } \\
\text { bined system } \\
\text { with wooden } \\
\text { shores }\end{array}$} & & \multirow[b]{2}{*}{$\alpha=1$} & $\begin{array}{c}\text { NWSB2D } \alpha=1 \\
(\text { NWSB2DT) }\end{array}$ & $\mathrm{kN}$ & $\begin{array}{c}47.758 \\
(36.324) \\
\end{array}$ & $\begin{array}{c}45.042 \\
(33.009) \\
\end{array}$ & $\begin{array}{c}46.400 \\
(34.667) \\
\end{array}$ & \multirow[b]{2}{*}{50.02} & \multirow[b]{2}{*}{$-7.8 \%$} \\
\hline & & & & Deformation & $\mathrm{mm}$ & $\begin{array}{l}10.062 \\
(7.431)\end{array}$ & $\begin{array}{l}8.810 \\
(7.150)\end{array}$ & $\begin{array}{l}9.436 \\
(7.291)\end{array}$ & & \\
\hline \multirow[t]{2}{*}{2} & & & \multirow[t]{2}{*}{$\alpha=0.382$} & $\begin{array}{c}\text { NWSB2D } \alpha= \\
0.382(38.5 \mathrm{~cm}) \\
(\mathrm{NWSB} 2 \mathrm{DT})\end{array}$ & $\mathrm{kN}$ & $\begin{array}{c}47.670 \\
(32.980)\end{array}$ & $\begin{array}{c}49.631 \\
(29.773)\end{array}$ & $\begin{array}{c}48.651 \\
(31.377)\end{array}$ & \multirow[t]{2}{*}{51.00} & \multirow[t]{2}{*}{$-4.8 \%$} \\
\hline & & & & Deformation & $\mathrm{mm}$ & $\begin{array}{c}9.246 \\
(7.387)\end{array}$ & $\begin{array}{l}11.347 \\
(7.912)\end{array}$ & $\begin{array}{l}10.297 \\
(7.650)\end{array}$ & & \\
\hline
\end{tabular}

Notes:

1. Data in parentheses denote test values of the second load after the scaffolding system is unloaded and then reloaded.

2. $\alpha$ denotes the ratio of the length of longer wooden shores to that of the scaffold unit.

3. In numerical analysis, the joint stiffness between the wooden shores and the steel scaffolds:

$\alpha=1.0, \mathrm{ks}=250 \mathrm{kN}-\mathrm{cm} / \mathrm{rad} ; \alpha=0.382, \mathrm{ks}=750 \mathrm{kN}-\mathrm{cm} / \mathrm{rad}$.

Based on the stiffnesses of various joints of previous scaffolding systems in the second-order elastic analysis, the critical load of this scaffolding system was obtained as $74.49 \mathrm{kN}$. As shown in Table 1, the analysis value, $74.49 \mathrm{kN}$, is close to the test value, $78.179 \mathrm{kN}$. The deviation of both values is around $4.7 \%$. Additionally, in the analysis, the deformation of the scaffolding system with extended adjustable U-head jacks and base jacks is similar to that of the scaffolding system being tested.

\subsection{Two-story combined system of scaffolds with wooden shores}

\subsubsection{Top wooden shores of the same length $(\alpha=1.0)$}

A two-story scaffolding system with four wooden shores of the same length $(170 \mathrm{~cm})$ on the top was adopted $(\alpha=1.0)$ in the experiment. Therefore, the total height of the structural system was the same as a three-story scaffolding system. As shown in Table 2, the mean critical load of these two scaffolding systems is $46.400 \mathrm{kN}$. Fig. 16 shows the deformation of the scaffolding system after loading. As shown in Fig. 16, the buckling failure of the combined system of scaffolds with wooden shores mainly occurs in the in-plane direction; the maximum horizontal deformation mainly occurs at the junction of the top scaffolds and the wooden shores, which is also in the in-plane direction. After unloading the first load, the mean critical load of the second load was taken as $34.667 \mathrm{kN}$, and the deformation of the scaffolding system also mainly occurred in the in-plane direction.

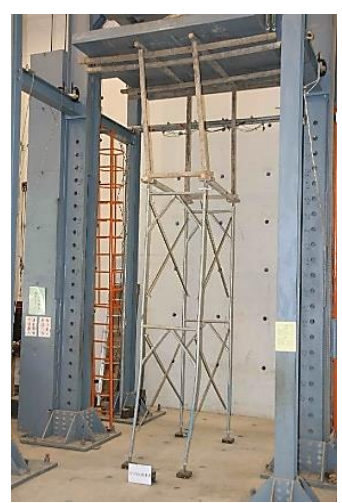

Fig. 16 Deformation of the combined system of scaffolds with wooden shores $(\alpha=1)$ after loading

As shown in Fig. 15, the critical load of the two-story combined system of scaffolds with wooden shores is $46.400 \mathrm{kN}$, which is around 0.43 (= 46.4/107.383) times the magnitude of the two-story scaffolding system with a basic configuration $(107.383 \mathrm{kN})$. This indicats that when $170 \mathrm{~cm}$ wooden shores are set up on top of the two-story scaffolding system, the load-bearing capacity of the scaffolding system reduces to around half. Therefore, regarding the use of scaffolding systems on construction sites, it is advisable to avoid adopting the combined system of scaffolds with wooden shores.

In the analysis of the combined system of scaffolds with wooden shores, the stiffnesses of various joints of previous scaffolding systems are adopted (as shown in Fig. 9(B)). With reference to the joint stiffness of scaffolding systems, the joint stiffness $\left(k_{S 3}\right)$ of the combined system of scaffolds with wooden shores is adopted as $250 \mathrm{kN}-\mathrm{cm} / \mathrm{rad}$. In the second-order elastic analysis, the critical load of the combined system of scaffolds with wooden shores is obtained as $50.02 \mathrm{kN}$ (as shown in Table 2). Fig. 17(A) shows the deformation of the combined system of scaffolds with wooden shores after loading, which is similar to that of the combined system of scaffolds with wooden shores shown in Fig. 16. Fig. 17(B) shows the relationship between the total vertical load and horizontal displacement at point A of the combined system of scaffolds with wooden shores. The analysis value, $50.02 \mathrm{kN}$, is close to the test value, 46.400 $\mathrm{kN}$. The deviation of both values is around $-7.8 \%$.

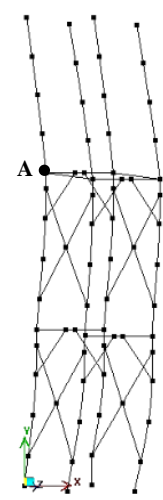

(A) Deformation after loading

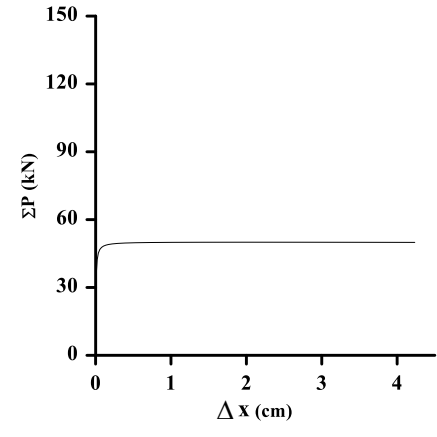

(B) Load vs. horizontal displacement diagram
Fig. 17 Results of the second-order elastic analysis with semi-rigid joints of the two-story combined system of scaffolds with wooden shores $(\alpha=1)$

6.2.2. Top wooden shores of the same length $(\alpha=0.382)$

A two-story scaffolding system with four wooden shores of the same but shorter lengths on the top was adopted $(\alpha=0.382)$ in the experiment. As shown in Table 2, the mean critical load of these two scaffolding systems is $48.651 \mathrm{kN}$. Fig. 18 shows that the deformation of the combined system of scaffolds with wooden shores mainly occurs in the in-plane direction of the back-row scaffolds, which is similar to that of the combined system of scaffolds with wooden shores of $170 \mathrm{~cm}$ in length. Similarly, the second loading tests were conducted on the scaffolding structures. The mean critical load is obtained as $31.377 \mathrm{kN}$, as shown in Table 2.

As shown in Fig. 15, the critical load, $48.651 \mathrm{kN}$, of the two-story combined system of scaffolds with shorter wooden shores $(\alpha=0.382)$ is close to that $(46.400 \mathrm{kN})$ of the two-story combined system of scaffolds with wooden shores of $170 \mathrm{~cm}$ in length $(\alpha=1.0)$

As shown in Fig. 15, under the same condition of height, the critical load, $48.651 \mathrm{kN}$, of the two-story combined system of scaffolds with shorter wooden shores $(\alpha=0.382)$ is $0.44(=48.651 / 109.903)$ of that of the scaffolding system with adjustable U-head jacks extended to $65 \mathrm{~cm}, 109.903 \mathrm{kN}$. Therefore, it is advisable to consider extending adjustable U-head jacks on the top of the scaffolding system instead of adopting the combined system of scaffolds with wooden shores. 


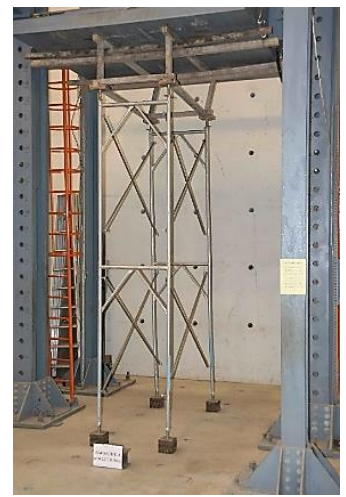

Fig. 18 Deformation of the combined system of scaffolds with wooden shores $(\alpha=0.382)$ after loading

The stiffnesses of various joints of previous scaffolding systems are adopted in the analysis. Based on the results of previous studies on scaffolding systems, it is observed that the shorter the wooden shores on the top of the combined system, the greater the joint stiffness at the junction of the scaffolds and the wooden shores. As shown in Fig. 9(B), the joint stiffness $\left(k_{S 3}\right)$ of the combined system of scaffolds with wooden shores is adopted as $750 \mathrm{kN}-\mathrm{cm} / \mathrm{rad}$. In the second-order elastic analysis, the critical load of the combined system of scaffolds with wooden shores is obtained as $51.00 \mathrm{kN}$ (as shown in Table 2). The deformation model obtained in the analysis is similar to that obtained in the testing described in Fig. 18. The analysis value, $51.00 \mathrm{kN}$, is close to the test value, $48.651 \mathrm{kN}$. The deviation of both values is around $-4.8 \%$.

Table 3

Test results of the combined system of scaffolds with wooden shores with different inclined planes

\begin{tabular}{|c|c|c|c|c|c|c|c|c|c|c|c|c|}
\hline \multirow[b]{2}{*}{ Item } & \multirow[b]{2}{*}{ Type } & \multirow{2}{*}{\multicolumn{2}{|c|}{ Fig-ure }} & \multirow{2}{*}{$\begin{array}{l}\text { Configu- } \\
\text { ration }\end{array}$} & \multirow[b]{2}{*}{ Numbering } & \multirow[b]{2}{*}{ Unit } & \multicolumn{4}{|c|}{ (a).Test value } & \multirow{2}{*}{$\begin{array}{l}\text { (b).Analy- } \\
\text { sis }(\mathrm{kN})\end{array}$} & \multirow{2}{*}{$\begin{array}{l}((a-b) / a) \\
\times 100 \%\end{array}$} \\
\hline & & & & & & & Group A & Group B & Group C & Mean & & \\
\hline \multirow{2}{*}{1} & \multirow{4}{*}{ Upper slope } & \multirow{4}{*}{$\frac{\stackrel{\Xi}{\Xi}}{\stackrel{1}{!}}$} & & \multirow{2}{*}{$\begin{array}{c}\text { In-plane } \\
\theta=30^{\circ} \\
\alpha=1\end{array}$} & $\begin{array}{c}\text { WSDUIY } \\
\theta=30^{\circ}, \alpha=1 \\
(\text { WSDUIYT) }\end{array}$ & $\mathrm{kN}$ & $\begin{array}{c}30.303 \\
(30.508)\end{array}$ & $\begin{array}{c}42.129 \\
(40.080)\end{array}$ & $\begin{array}{c}30.773 \\
(27.478)\end{array}$ & $\begin{array}{c}34.402 \\
(32.689)\end{array}$ & \multirow{2}{*}{32.56} & \multirow{2}{*}{$5.4 \%$} \\
\hline & & & & & Deformation & $\mathrm{mm}$ & $\begin{array}{c}14.894 \\
(15.012)\end{array}$ & $\begin{array}{c}13.406 \\
(14.950)\end{array}$ & $\begin{array}{c}13.225 \\
(15.612)\end{array}$ & $\begin{array}{c}13.842 \\
(15.191)\end{array}$ & & \\
\hline \multirow{2}{*}{2} & & & & \multirow{2}{*}{$\begin{array}{c}\text { In-plane } \\
\theta=30^{\circ} \\
\alpha=0.32\end{array}$} & 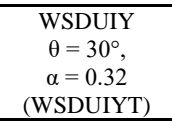 & $\mathrm{kN}$ & $\begin{array}{c}80.150 \\
(59.997)\end{array}$ & $\begin{array}{c}90.231 \\
(29.459)\end{array}$ & --- & $\begin{array}{c}85.191 \\
(44.728)\end{array}$ & \multirow{2}{*}{85.52} & \multirow{2}{*}{$-0.4 \%$} \\
\hline & & & & & Deformation & $\mathrm{mm}$ & $\begin{array}{c}24.232 \\
(16.517)\end{array}$ & $\begin{array}{c}24.819 \\
(15.731)\end{array}$ & --- & $\begin{array}{c}24.526 \\
(16.124)\end{array}$ & & \\
\hline \multirow{2}{*}{3} & \multirow{2}{*}{ Upper slope } & \multirow{2}{*}{$\begin{array}{l}\stackrel{0}{\Xi} \\
\frac{1}{2} \\
\frac{1}{0} \\
\stackrel{1}{\Xi} \\
0\end{array}$} & & \multirow{2}{*}{$\begin{array}{l}\text { Out-of -plane } \\
\qquad \begin{array}{c}\theta=30^{\circ} \\
\alpha=1\end{array}\end{array}$} & $\begin{array}{c}\text { WSDUIX } \\
\theta=30^{\circ}, \alpha=1 \\
(\text { WSDUIXT) }\end{array}$ & $\mathrm{kN}$ & $\begin{array}{c}45.130 \\
(36.000)\end{array}$ & $\begin{array}{c}41.463 \\
(36.491)\end{array}$ & -- & $\begin{array}{c}43.297 \\
(36.246)\end{array}$ & \multirow{2}{*}{47.27} & \multirow{2}{*}{$-9.2 \%$} \\
\hline & & & & & Deformation & $\mathrm{mm}$ & $\begin{array}{c}8.950 \\
(7.294)\end{array}$ & $\begin{array}{c}8.937 \\
(8.454)\end{array}$ & --- & $\begin{array}{c}8.944 \\
(7.874)\end{array}$ & & \\
\hline \multirow[t]{2}{*}{4} & \multirow{4}{*}{$\begin{array}{l}\text { Upper\& } \\
\text { Lower } \\
\text { slope }\end{array}$} & \multirow{2}{*}{$\frac{\mathscr{\Xi}}{\frac{\tilde{J}}{a}}$} & & \multirow{2}{*}{$\begin{array}{c}\text { In-plane } \\
\theta=30^{\circ} \\
\alpha=0.5 \\
\beta=0.15\end{array}$} & $\begin{array}{c}\text { WSDUGIJY } \\
\theta=30^{\circ}, \alpha=0.5 \\
\beta=0.15 \\
\text { (WSDUGIJYT) }\end{array}$ & $\mathrm{kN}$ & $\begin{array}{c}41.865 \\
(23.654)\end{array}$ & $\begin{array}{c}37.373 \\
(25.233)\end{array}$ & $\begin{array}{c}32.980 \\
(21.124)\end{array}$ & $\begin{array}{c}37.406 \\
(23.337)\end{array}$ & \multirow[t]{2}{*}{38.64} & \multirow[t]{2}{*}{$-3.3 \%$} \\
\hline & & & & & Deformation & $\mathrm{mm}$ & $\begin{array}{c}18.988 \\
(13.931)\end{array}$ & $\begin{array}{c}22.169 \\
(19.113)\end{array}$ & $\begin{array}{c}13.444 \\
(10.169)\end{array}$ & $\begin{array}{c}18.200 \\
(14.404)\end{array}$ & & \\
\hline \multirow[t]{2}{*}{5} & & \multirow{2}{*}{$\begin{array}{l}\frac{0}{3} \\
\frac{\pi}{2} \\
\frac{1}{0} \\
\frac{1}{3} \\
0\end{array}$} & & \multirow[t]{2}{*}{$\begin{array}{c}\text { Out-of -plane } \\
\begin{array}{c}\theta=30^{\circ} \\
\alpha=0.7 \\
\beta=0.15\end{array}\end{array}$} & $\begin{array}{c}\text { WSDUGIJX } \\
\theta=30^{\circ}, \\
\alpha=0.7 \\
\beta=0.15 \\
\text { (WSDUGIJXT) }\end{array}$ & $\mathrm{kN}$ & $\begin{array}{c}50.249 \\
(34.637)\end{array}$ & $\begin{array}{c}45.101 \\
(31.970)\end{array}$ & $\begin{array}{c}47.778 \\
(33.558)\end{array}$ & $\begin{array}{c}47.709 \\
(33.388)\end{array}$ & \multirow[t]{2}{*}{43.05} & \multirow[t]{2}{*}{$9.8 \%$} \\
\hline & & & & & Deformation & $\mathrm{mm}$ & $\begin{array}{l}12.550 \\
(8.216)\end{array}$ & $\begin{array}{l}10.887 \\
(8.783)\end{array}$ & $\begin{array}{l}10.309 \\
(8.272)\end{array}$ & $\begin{array}{l}11.249 \\
(8.424) \\
\end{array}$ & & \\
\hline
\end{tabular}

Notes:

1. Data in parentheses denote test values of the second load after the scaffolding system is unloaded and then reloaded.

2. $\alpha$ denotes the ratio of the length of longer wooden shores to that of the scaffold unit; $\beta$ denotes the ratio of the length of the extended base jacks to that of the scaffold unit.

3. The angle of inclination of the ceiling slab $\theta=30^{\circ}$.

4. In numerical analysis, the joint stiffness of the steel scaffolds is $2500 \mathrm{kN}-\mathrm{cm} / \mathrm{rad}$; that of the adjustable base and U-head jacks is $450 \mathrm{kN}-\mathrm{cm} / \mathrm{rad}$

Joint stiffness between the wooden shores and steel scaffolds:

$\alpha=1.0, \mathrm{ks}=250 \mathrm{kN}-\mathrm{cm} / \mathrm{rad} ; \alpha=0.7, \mathrm{ks}=450 \mathrm{kN}-\mathrm{cm} / \mathrm{rad} ; \alpha=0.5, \mathrm{ks}=500 \mathrm{kN}-\mathrm{cm} / \mathrm{rad} ; \alpha=0.32, \mathrm{ks}=1500 \mathrm{kN}-\mathrm{cm} / \mathrm{rad}$

Setup of top linear springs (in-plane): inclination (weak direction), $\mathrm{kx}=0.1 \mathrm{kN} / \mathrm{cm}$; inclination (strong direction), $\mathrm{k}_{\mathrm{z}}=1 \mathrm{kN} / \mathrm{cm}$

Setup of top linear springs (out-of-plane): inclination (weak direction): $3 \mathrm{kN} / \mathrm{cm}$; inclination (strong direction): $30 \mathrm{kN} / \mathrm{cm}$ 


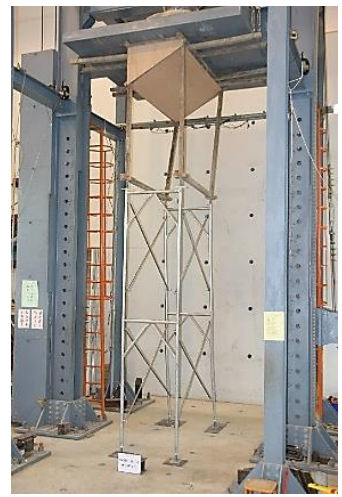

Fig. 19 Deformation of the combined system of scaffolds with wooden shores under inclined slab after loading $\left(\alpha=1.0 / \theta=30^{\circ}\right.$ in the in-plane direction $)$

The stiffnesses of various joints of previous scaffolding systems, as well as those of the adjustable base jacks and U-head jacks, are adopted in the analysis (as shown in Fig. 20(A)). The joint stiffness $\left(k_{S 3}\right)$ at the junction of the scaffolds and the wooden shores is adopted as $250 \mathrm{kN}-\mathrm{cm} / \mathrm{rad}$. Since the junction of the top of the wooden shores and the inclined ceiling slab cannot be perfectly fixed, some horizontal displacement might occur after loading. Therefore, linear springs are used to simulate the situation during analysis. The stiffness $\left(k_{X}\right)$ of the linear springs used in this study is $0.1 \mathrm{kN} / \mathrm{cm}$ in the inclination direction (xyplane) and $1 \mathrm{kN} / \mathrm{cm}$ in the yz-plane. The definition of these linear springs is shown in Fig. 20(A)

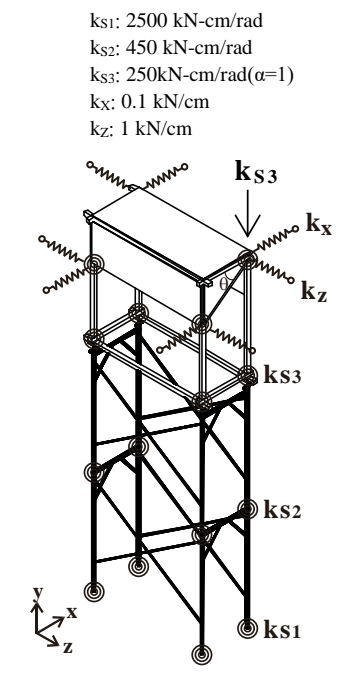

(A) Ceiling slab inclining in the in-plane direction $\mathrm{k}_{\mathrm{s} 1}: 2500 \mathrm{kN}-\mathrm{cm} / \mathrm{rad}$

$\mathrm{k}_{\mathrm{s} 2}: 450 \mathrm{kN}-\mathrm{cm} / \mathrm{rad}$

$\mathrm{k}_{\mathrm{S} 3}: 250 \mathrm{kN}-\mathrm{cm} / \mathrm{rad}(\alpha=1)$

$\mathrm{kx}_{\mathrm{x}}: 30 \mathrm{kN} / \mathrm{cm}$

$\mathrm{k}_{\mathrm{z}:} 3 \mathrm{kN} / \mathrm{cm}$

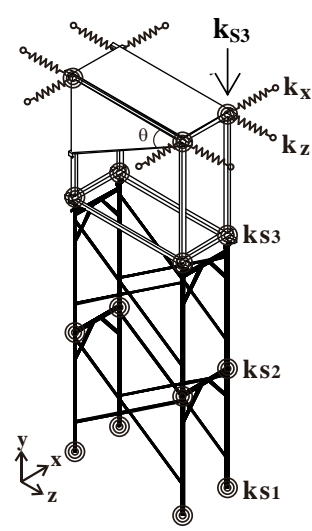

(B) Ceiling slab inclining in the out-ofplane direction
Fig. 20 Schematic diagram of the positions of different joint stiffnesses in the combined system of scaffolds with wooden shores in different inclined planes

In second-order elastic analysis with semi-rigid joints, the critical load of the scaffolding system is obtained as $32.56 \mathrm{kN}$ (as shown in Table 3). Fig. 21(A) shows the deformation of the combined system of scaffolds with wooden shores with the ceiling slab inclining in the in-plane direction (xy-plane) after loading, which is similar to that of the scaffolding system tested in Fig. 19. Fig. 21(B) shows the relationship between the total vertical load and horizontal displacement on point $\mathrm{A}$ of the scaffolding system. The analysis value, 32.56 $\mathrm{kN}$, is very close to the test value, $34.402 \mathrm{kN}$. The deviation of both values is around $5.4 \%$.

- Situation of long wooden shores with $\alpha=0.32$

The configuration of the scaffolding system with the "situation of long wooden shores with $\alpha=0.32$ " in the experiment is the same as that of the scaffolding system with the "situation of long wooden shores with $\alpha=1.0$ ", except that the wooden shores are of different lengths. The scaffold configuration is defined as the "situation of long wooden shores with $\alpha=0.32$ ", namely, the longest wooden shores are $54.4 \mathrm{~cm}$ and the ceiling slab is inclined with a downward angle $30^{\circ}$ (as shown in Fig. 5(A)). As shown in Table 3, the test results show that the mean critical load of the two scaffolding systems is $85.191 \mathrm{kN}$. The deformation of the combined system of scaffolds with wooden shores mainly occurs in the in-plane direction and the maximum horizontal deformation mainly occurs at the junction of the scaffolds and the wooden shores. Similarly, the second loading test is conducted on the scaffolding structures and the mean critical load is obtained as $44.728 \mathrm{kN}$. The buckling failure of the scaffolding structure in the second loading test is similar to that of the first loading test, which also occurs in the in-plane direction.

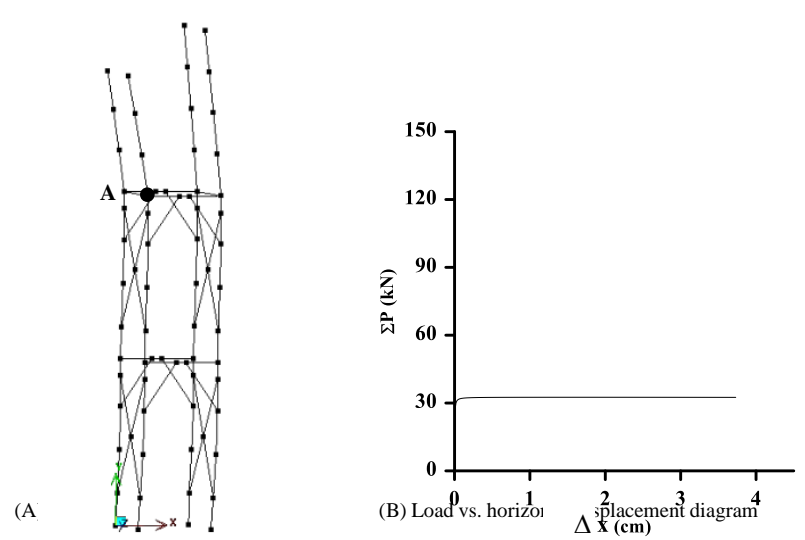

Fig. 21 Results of the second-order elastic analysis with semi-rigid joints of the scaffolding system with the ceiling slab inclining in the in-plane direction ( $x y$-plane) $\left(\alpha=1.0 / \theta=30^{\circ}\right.$ in the in-plane direction)

For the scaffolding systems underneath an inclined plane in the in-plane direction, the critical load of the scaffolding system with long wooden shores with $\alpha=0.32$ is $85.191 \mathrm{kN}$, which is $2.47(=85.191 / 34.402)$ times that of the scaffolding system with long wooden shores with $\alpha=1.0(34.402 \mathrm{kN})$, indicating that the combined system of scaffolds with shorter wooden shores has a greater load-bearing capacity.

The stiffnesses of various joints obtained from previous scaffolding systems were adopted in the analysis. The definitions of various joints are shown in Fig. 20(A). Since the wooden shores in the scaffolding system are shorter, the joint stiffness $\left(k_{S 3}\right)$ at the junction of the top of the scaffolds and the wooden shores is defined as $1500 \mathrm{kN}-\mathrm{cm} / \mathrm{rad}$. Linear springs are used to simulate the junction of the top of the wooden shores and the inclined ceiling slab. The stiffness $\left(k_{X}\right)$ of the linear springs is $0.1 \mathrm{kN} / \mathrm{cm}$ in the inclination direction ( $x y$-plane) and the stiffness $\left(k_{Z}\right)$ is $1 \mathrm{kN} / \mathrm{cm}$ in the $y z$-plane. The definitions of these linear springs are shown in Fig. 20(A). In the second-order elastic analysis, the critical load of the scaffolding system is obtained as $85.52 \mathrm{kN}$ (as shown in Table 3). The deformation model obtained in the analysis is similar to that obtained in the tests as described in Fig. 19. The analysis value, $85.52 \mathrm{kN}$, is close to the test value, $85.191 \mathrm{kN}$. The deviation of both values is around $-0.4 \%$.

\subsubsection{Ceiling slab inclined in the out-of-plane direction (yz-plane) $(\alpha=1.0)$}

The configuration of the scaffolding system with different lengths of wooden shores on the top of the scaffold is shown in Fig. 5(B), which is under a ceiling slab inclined in the out-of-plane direction of the scaffold. In the experiment, $\alpha=1.0$ is defined for the two longest wooden shores $(170 \mathrm{~cm})$ used to fit a ceiling slab inclined in the out-of-plane direction by $30^{\circ}$ downward (as shown in Fig. 5(B)). As shown in Table 3, the test yields a mean critical load of $43.297 \mathrm{kN}$.

Fig. 22 shows the deformation of the test configuration after loading, which mainly occurs in the back row of the shorter wooden shores in the in-plane direction. The maximum horizontal deformation occurs at the junction of the scaffolds and the wooden shores. The deformation of the test configuration after loading is unique, in that the deformation first occurs in the out-of-plane direction and then switches to the in-plane direction until the structure fails. After the second loading test, the mean critical load was obtained as $36.246 \mathrm{kN}$ The buckling failure occurred in the in-plane direction of the scaffolding system, which was similar to that of the first loading test. 


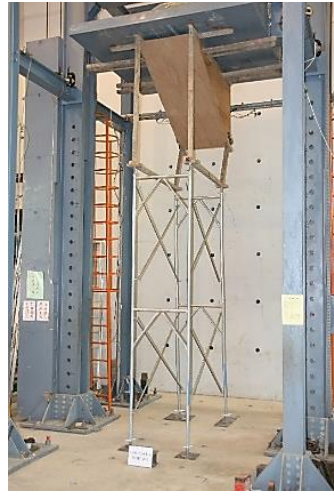

Fig. 22 Deformation of the combined system of scaffolds with wooden shores under inclined slab after loading $\left(\alpha=1.0 / \theta=30^{\circ}\right.$ in the out-of-plane direction

By dividing the critical load of the scaffolding system with the ceiling slab inclined in the out-of-plane direction $(43.297 \mathrm{kN})$ by that of the combined system of scaffolds with wooden shores with the ceiling slab inclined in the inplane direction $(34.402 \mathrm{kN})$, the ratio $1.26(=43.297 / 34.402)$ is obtained. Thus, in the case of a combined system of scaffolds with wooden shores to be set up under an inclined ceiling slab on a construction site, it is advisable to set it up in the out-of-plane direction (as shown in Fig. 5(B)).

Fig. 23 integrates the test results as described in Table 2 and Table 3, which makes a comparison of the test values of the combined systems underneath a flat ceiling slab and those underneath an inclined ceiling slab. As shown in Fig. 23 , by dividing the critical load of the combined system of the scaffolds with wooden shores with the ceiling slab inclining in the out-of-plane direction $(43.297 \mathrm{kN})$ by that of the combined system of scaffolds with wooden shores with a flat ceiling slab $(46.4 \mathrm{kN})$, the ratio $0.93(=43.297 / 46.4)$ is obtained. This indicates that the load-bearing capacities of these two scaffold configurations were quite close.

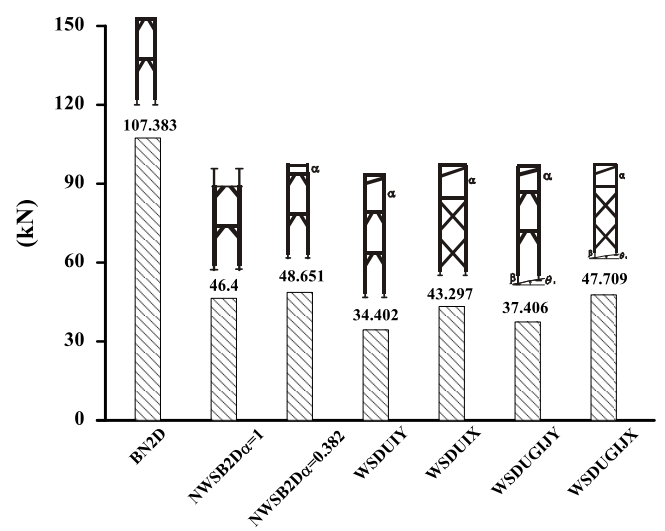

Fig. 23 Comparison of critical loads of the combined systems of scaffolds with wooden shores underneath an inclined plane of different angles and on different ground situation

The stiffnesses of various joints in the previous scaffolding systems were adopted in the analysis. The definition of the joint stiffness is shown in Fig. 20(B). The joint stiffness $\left(k_{S 3}\right)$ at the junction of the scaffolds and the wooden shores was set as $250 \mathrm{kN}-\mathrm{cm} / \mathrm{rad}$. The joint type between the wooden shore and the ceiling slab inclined in the out-of-plane direction is different from that inclined in the in-plane direction, as shown from previous inclined ceiling slab tests.

As shown in these inclined ceiling slab tests, the stiffness at the junction of the wooden shores and the ceiling slab inclined in the out-of-plane direction is greater than that of the junction of the wooden shores and the ceiling slab inclined in the in-plane direction. The stiffness $\left(k_{Z}\right)$ of the linear springs adopted in this analysis is $3 \mathrm{kN}$-cm in the $y z$-plane, and the stiffness $\left(k_{X}\right)$ in the $x y$-plane is $30 \mathrm{kN}-\mathrm{cm}$. The definitions of these linear springs are shown in Fig. 20(B)

From the second-order elastic analysis, the critical load of the scaffolding system was obtained as $42.27 \mathrm{kN}$ (as shown in Table 3). Fig. 24(A) shows the deformation of the combined system of scaffolds with wooden shores after loading with the ceiling slab inclining in the out-of-plane direction (yz-plane), which is similar to that of the scaffold configuration shown in Fig. 22. Fig. 24(B) shows the relationship between the total vertical load and horizontal displacement at point A of the scaffolding system. The analysis value, $42.27 \mathrm{kN}$, is close to the test value, $43.297 \mathrm{kN}$. The deviation of both values is around $-9.2 \%$

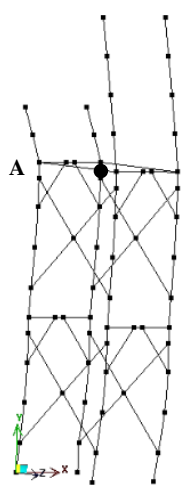

(A) Deformation after loading

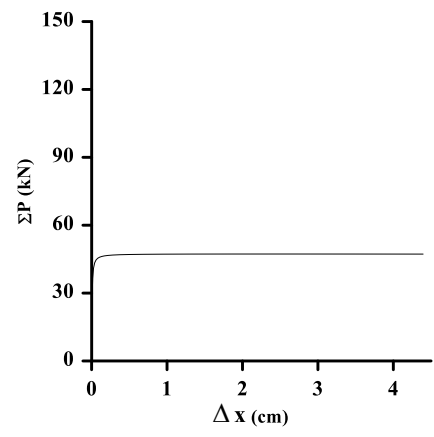

(B) Load vs. horizontal displacement diagram
Fig. 24 Results of the second-order elastic analysis with semi-rigid joints of the scaffolding system with the ceiling slab inclining in the out-of-plane direction ( $y z$-plane) $(\alpha=1.0)$

6.2.5. Ceiling slab inclined in the in-plane direction (xy-plane) $(\alpha=0.5)$ with elevation difference on the ground surface $(\beta=0.15)$

The test configuration consists of a ceiling slab inclined in the in-plane direction ( $x y$-plane) with an elevation difference on the ground surface, as shown in Fig. 6(A). In Fig. 6(A), the longer wooden shores of $85 \mathrm{~cm}(=0.5 \times 170$ $\mathrm{cm}$ ) are used with $\alpha=0.5$, and the ceiling slab is inclined downward with an angle $30^{\circ}$ in the in-plane direction. The definition of ' $\beta=0.15$ ' indicates that there is an elevation difference of $25.5 \mathrm{~cm}(=0.15 \times 170 \mathrm{~cm})$ on the ground due to the extension of the base jacks, as shown in Fig. 6(A). Since the deviations between the first two tests are quite large, the third test is conducted. Then, a mean critical load of $37.406 \mathrm{kN}$ is obtained, as shown in Table 3.

Fig. 25 shows the deformation of the scaffolding system after loading, which mainly occurs in the front row of the scaffolds and in the in-plane direction. Again, the maximum horizontal deformation occurred at the junction of the scaffolds and the wooden shores. The mean critical load of the second loading test was obtained as $23.337 \mathrm{kN}$. The buckling failure of the scaffolding system in the second loading test was similar to that in the first loading test, and the deformation also mainly occurred in the in-plane direction.

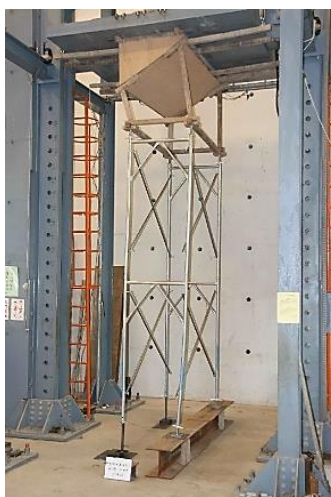

Fig. 25 Deformation of the combined system of scaffolds with wooden shores under inclined slab and uneven base after loading $\left(\alpha=0.5 / \beta=0.15 / \theta=30^{\circ}\right.$ in the in-plane direction)

In the analysis, the stiffnesses of the various joints of the previous scaffolding systems were adopted. The definitions of the joint stiffnesses are shown in Fig. 20(A). Additionally, the joint stiffness $\left(k_{S 3}\right)$ at the junction of the scaffolds and the wooden shores was adopted as $500 \mathrm{kN}-\mathrm{cm} / \mathrm{rad}$. In this test, since the ceiling slab was inclined in the in-plane direction, linear springs were used to simulate the junction of the wooden shores and the inclined ceiling slab. The stiffness of the linear springs was $0.1 \mathrm{kN} / \mathrm{cm}\left(k_{X}\right)$ in the inclination direction (xy-plane) and $1 \mathrm{kN} / \mathrm{cm}\left(k_{\mathrm{Z}}\right)$ in the $y z$-plane. The definition of these linear springs is shown in Fig. 20(A).

From the second-order elastic analysis, the critical load of the scaffolding system is obtained as $38.64 \mathrm{kN}$, as shown in Table 3. The deformation model obtained in the analysis is similar to that obtained in the tests as described in Fig. 25. The analysis value, $38.64 \mathrm{kN}$, is close to the test value, $37.406 \mathrm{kN}$. The deviation of both values is around $-3.3 \%$ 
6.2.6. Ceiling slab inclined in the out-of-plane direction (yz-plane) $(\alpha=0.7)$ with elevation difference on the ground surface $(\beta=0.15)$

In this test, the scaffolding system configuration consists of a ceiling slab inclined in the out-of-plane direction ( $y z$-plane) and an elevation difference on the ground, as shown in Fig. 6(B). In Fig. 6(B), the longer wooden shores of $119 \mathrm{~cm}(=0.7 \times 170 \mathrm{~cm})$ with $\alpha=0.7$ are adopted, and the ceiling slab is inclined downward with an angle $30^{\circ}$ in the out-of-plane direction. The definition of ' $\beta$ $=0.15^{\prime}$ indicats that there is an elevation difference of $25.5 \mathrm{~cm}(=0.15 \times 170 \mathrm{~cm})$ on the ground due to the extension of the base jacks, as shown in Fig. 6(B). Since the deviations of the first two tests are quite large, the third test is conducted. A mean critical load of $47.709 \mathrm{kN}$ is obtained, as shown in Table 3.

Fig. 26 shows the deformation of the test configuration after loading, which mainly occurs in the front row of scaffolds and in the in-plane direction. The maximum horizontal deformation occurs at the junction of the scaffolds and the wooden shores. Similarly, the mean critical load of the second loading test is obtained as $33.388 \mathrm{kN}$. The buckling failure of the scaffolding structure in the second loading test is similar to that in the first loading test, and the deformation mainly occurs in the in-plane direction.

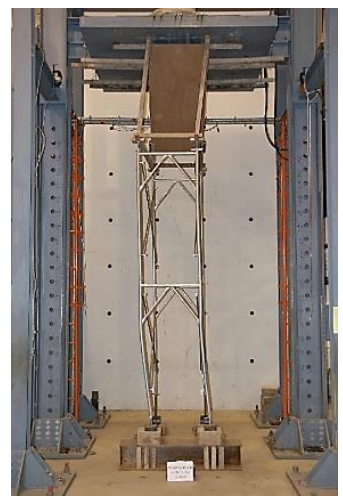

Fig. 26 Deformation of the combined system of scaffolds with wooden shores under inclined slab and uneven base after loading $\left(\alpha=0.7 / \beta=0.15 / \theta=30^{\circ}\right.$ in the out-of-plane direction)

As shown in Table 3 and Fig. 23, the case of the combined system with the ceiling slab inclined in the out-of-plane direction and an elevation difference on the ground produces a critical load of $47.709 \mathrm{kN}$, while the case with the ceiling slab inclined in the in-plane direction and an elevation difference on the ground produces a critical load of $37.406 \mathrm{kN}$. The ratio of the two values is $1.28(=$ 47.709/37.406). Additionally, the critical load of the former scaffolding configuration $(47.709 \mathrm{kN})$ is very close to that of the combined system of scaffolds with wooden shores with a flat ceiling slab $(46.4 \mathrm{kN})$.

In the analysis, the stiffnesses of various joints of the previous scaffolding systems were adopted. The definition of joint stiffness is shown in Fig. 20(B). The joint stiffness $\left(k_{s 3}\right)$ at the junction of the scaffolds and the wooden shores is adopted as $450 \mathrm{kN}-\mathrm{cm} / \mathrm{rad}$. In this test, since the ceiling slab is inclined in the out-of-plane direction, linear springs are used to simulate the junction of the wooden shores and the inclined ceiling slab. The stiffness of the linear springs is $3 \mathrm{kN}-\mathrm{cm}\left(k_{z}\right)$ in the inclination direction (yz-plane) and $30 \mathrm{kN}-\mathrm{cm}\left(k_{X}\right)$ in the $x y$-plane. The definition of these linear springs is shown in Fig. 20(B).

From the second-order elastic analysis, the critical load of the scaffolding system is obtained as $43.05 \mathrm{kN}$, as shown in Table 3. The deformation model obtained in the analysis is similar to that obtained in the tests described in Fig. 26. The analysis value, $43.05 \mathrm{kN}$, is close to the test value, $47.709 \mathrm{kN}$. The deviation of both values is around $9.8 \%$.

In conclusion, it is observed that the critical load of the combined system of scaffolds with wooden shores, the ceiling slab inclined in the out-of-plane direction, and an elevation difference on the ground is greater than that of the same scaffold configuration with a ceiling slab inclined in the in-plane direction. Therefore, in the case of an inclined ceiling slab and an elevation difference on the ground, it is advisable to set up the top inclined ceiling slab in the out-ofplane direction of the scaffolds on construction sites, as shown in Fig. 6(B).

\subsection{Lower bound of load-bearing capacity of the repeatedly used scaffolds}

\subsubsection{The scaffolding system}

In this study, two loading tests were conducted on various scaffolding systems. The critical load obtained in the second loading test is considered as the lower bound of the load-bearing capacity of the scaffolding systems installed by reused scaffolds. The strength reduction factor $(\phi)$ of the scaffolding systems installed by reused scaffolds is calculated by dividing the critical load of the second loading test by that of the first loading test. As shown in Table 4, the mean value $\left(\mu_{\phi}\right)$ of the strength reduction factor $(\phi)$ of the door-type reused steel scaffolds is around 0.79 and the standard deviation $(\sigma)$ is around 0.07 .
Table 4

Critical load of various scaffolding systems in the first and the second loading tests, and the ratio $\phi$

\begin{tabular}{|c|c|c|c|c|c|c|}
\hline \multirow[b]{2}{*}{ Item } & \multirow[b]{2}{*}{ Numbering } & \multicolumn{2}{|c|}{ Test value $(\mathrm{kN})$} & \multirow[b]{2}{*}{$\begin{array}{c}\phi= \\
(\mathrm{B}) /(\mathrm{A})\end{array}$} & \multirow{2}{*}{$\begin{array}{c}\mu_{\phi} \\
\text { Mean } \\
\text { value }\end{array}$} & \multirow{2}{*}{$\begin{array}{c}\sigma_{\phi} \\
\text { Standard } \\
\text { deviation }\end{array}$} \\
\hline & & $\begin{array}{l}\text { First load- } \\
\text { bearing } \\
\text { capacity (A) }\end{array}$ & $\begin{array}{l}\text { Second load- } \\
\text { bearing } \\
\text { capacity (B) }\end{array}$ & & & \\
\hline 1 & BN2D-A & 108.80 & 96.38 & 0.886 & \multirow{6}{*}{0.791} & \multirow{6}{*}{0.071} \\
\hline 2 & BN2D-B & 105.97 & 90.90 & 0.858 & & \\
\hline 3 & Uj65D-A & 111.79 & 79.34 & 0.710 & & \\
\hline 4 & Uj65D-B & 108.02 & 83.03 & 0.769 & & \\
\hline 5 & Uj65J65D-A & 81.35 & 65.38 & 0.804 & & \\
\hline 6 & Uj65J65D-B & 75.01 & 54.21 & 0.723 & & \\
\hline
\end{tabular}

Subtracting one standard deviation from the mean value of the strength reduction factor of the scaffolding system installed by reused scaffolds, $\phi$ gives $0.72\left(\phi=\mu_{\phi}-\sigma_{\phi}=0.79-0.07\right)$; similarly, subtracting two standard deviations from that, $\phi$ gives $0.65\left(\phi=\mu_{\phi}-2 \sigma_{\phi}=0.79-2 \times 0.07\right)$; subtracting three standard deviations from that, $\phi$ gives $0.58\left(\phi=\mu_{\phi}-3 \sigma_{\phi}=0.79-3 \times 0.07\right)$. Based on the on-site safety requirements, any of the above three strength reduction factors $(\phi)$ can be multiplied by the load-bearing capacity of the scaffolding system installed by new scaffolds to obtain the lower bound of the load-bearing capacity of the door-type reused steel scaffolds. This can serve as a reference for the strength design of the scaffolding system.

\subsubsection{The combined system of scaffolds with wooden shore}

Table 5 shows the critical loads of the combined system of scaffolds with wooden shores in the first and second loading tests, as well as the ratio $(\phi)$ of the critical load in the second loading test to that in the first loading test. This ratio $(\phi)$ can be considered as the strength reduction factor of the combined system of scaffolds with wooden shores installed by reused scaffolds. As shown in Table 5 , the mean value $\left(\mu_{\phi}\right)$ of the strength reduction factor of the combined system of scaffolds with wooden shores $(\phi)$ is around 0.73 and the standard deviation $\left(\sigma_{\phi}\right)$ is around 0.16 .

Subtracting one standard deviation from the mean value of the strength reduction factor of the combined system of scaffolds with wooden shores installed by reused scaffolds, $\phi$ gives $0.57\left(\phi=\mu_{\phi}-\sigma_{\phi}=0.73-0.16\right)$; subtracting two standard deviations from that, $\phi$ gives $0.41\left(\phi=\mu_{\phi}-2 \sigma_{\phi}=0.73\right.$ $-2 \times 0.16)$; subtracting three standard deviations from that, $\phi$ gives 0.25 ( $\phi=\mu_{\phi}$ $-3 \sigma_{\phi}=0.73-3 \times 0.16$ ). To satisfy the on-site safety requirements, any of the above three strength reduction factors $(\phi)$ can serve as a reference for the strength design of the combined system of scaffolds with wooden shores.

\section{Table 5}

Critical load of various combined systems of scaffolds with wooden shores in the first and the second loading tests, and the ratio $\phi$

\begin{tabular}{|c|c|c|c|c|c|c|c|}
\hline \multirow[b]{2}{*}{ Item } & \multirow[b]{2}{*}{ Type } & \multirow[b]{2}{*}{ Numbering } & \multicolumn{2}{|c|}{ Test value $(\mathrm{kN})$} & \multirow[b]{2}{*}{$\begin{array}{c}\phi= \\
(\mathrm{B}) /(\mathrm{A})\end{array}$} & \multirow[b]{2}{*}{$\begin{array}{c}\mu_{\phi} \\
\text { Mean } \\
\text { value }\end{array}$} & \multirow[b]{2}{*}{$\begin{array}{c}\sigma_{\phi} \\
\text { Standard } \\
\text { deviation }\end{array}$} \\
\hline & & & $\begin{array}{c}\text { First } \\
\text { load- } \\
\text { bearing } \\
\text { capacity } \\
\text { (A) }\end{array}$ & $\begin{array}{l}\text { Second } \\
\text { load- } \\
\text { bearing } \\
\text { capacity } \\
\text { (B) }\end{array}$ & & & \\
\hline 1 & \multirow{2}{*}{$\alpha=1$} & NWSB2D1-A & 47.76 & 36.32 & 0.760 & \multirow{17}{*}{0.727} & \multirow{17}{*}{0.159} \\
\hline 2 & & NWSB2D1-B & 45.04 & 33.01 & 0.733 & & \\
\hline 3 & \multirow{2}{*}{$\begin{array}{c}\alpha= \\
0.382\end{array}$} & NWSB2D0.38-A & 47.67 & 32.98 & 0.692 & & \\
\hline 4 & & NWSB2D0.38-B & 49.631 & 29.773 & 0.600 & & \\
\hline 5 & \multirow{3}{*}{$\alpha=1$} & WSDUIY1-A & 30.303 & 30.508 & 1.007 & & \\
\hline 6 & & WSDUIY1-B & 42.129 & 40.08 & 0.951 & & \\
\hline 7 & & WSDUIY1-C & 30.773 & 27.478 & 0.893 & & \\
\hline 8 & \multirow{2}{*}{$\alpha=0.32$} & WSDUIY0.32-A & 81.150 & 59.997 & 0.739 & & \\
\hline 9 & & WSDUIY0.32-B & 90.231 & 29.459 & 0.326 & & \\
\hline 10 & \multirow{2}{*}{$\alpha=1$} & WSDUIX1-A & 45.130 & 36.000 & 0.798 & & \\
\hline 11 & & WSDUIX1-B & 41.463 & 36.491 & 0.880 & & \\
\hline 12 & \multirow{3}{*}{$\begin{array}{l}\alpha=0.5 \\
\beta=0.15\end{array}$} & WSDUGIJY-A & 41.865 & 23.654 & 0.565 & & \\
\hline 13 & & WSDUGIJY-B & 37.373 & 25.233 & 0.675 & & \\
\hline 14 & & WSDUGIJY-C & 32.98 & 21.124 & 0.641 & & \\
\hline 15 & \multirow{3}{*}{$\begin{array}{c}\alpha=0.7 \\
\beta=0.15\end{array}$} & WSDUGIJX-A & 50.249 & 34.637 & 0.689 & & \\
\hline 16 & & WSDUGIJX-B & 45.101 & 31.97 & 0.709 & & \\
\hline 17 & & WSDUGIJX-C & 47.778 & 33.558 & 0.702 & & \\
\hline
\end{tabular}




\section{Conclusions}

This study investigates the stability behavior of various scaffolding systems, including an inclined ceiling slab, adjustable U-head jacks, base jacks of different lengths, and an elevation difference on the ground surface. The loading tests and the second-order elastic analyses with semi-rigid joints are conducted, and the major findings of this study are summarized as follows:

1. When the adjustable U-head jacks are extended to $65 \mathrm{~cm}$, the load-bearing capacity of the entire scaffolding system is not changed obviously. When both the adjustable U-head jacks and adjustable base jacks are extended to $65 \mathrm{~cm}$, the load-bearing capacity of the scaffolding system is around $70 \%$ of that of the scaffolding system with a basic configuration. The loadbearing capacity of the scaffolding system with wooden shores of the same length, as an extension of the above adjustable U-head jacks, is around $40 \%$ of that of the scaffolding system with the adjustable U-head jacks extended to $65 \mathrm{~cm}$. Therefore, if the height of the scaffolding system needs to be extended by less than $65 \mathrm{~cm}$ on construction sites, it is advisable to consider extending adjustable U-head jacks to meet the purpose. Nevertheless, it is required to confirm the limit of extended adjustable Uhead jacks and base jacks in the following studies.

2. If wooden shores are used to adjust the height of the combined system of scaffolds with wooden shores under an inclined ceiling slab, the load-bearing capacity of the combined system under the inclined ceiling slab in the out-of-plane direction is greater than that of the same combined system under the inclined ceiling slab in the in-plane direction. Therefore, in the case of a combined system of scaffolds with wooden shores to be set up under an inclined ceiling slab, it is suggested that the system is set up in the out-of-plane direction of the scaffold.

3. Based on the loading test results for different configurations of scaffolding systems, similar analysis results can be obtained, provided that the appropriate stiffness values of various joints are appropriately selected in the "second-order elastic analysis with semi-rigid joints".

4. Based on the results of the loading tests on various scaffolding systems, the lower bound of load-bearing capacity of various systems installed by reused scaffolds can be obtained. By calculating the mean value and standard deviation of these lower bound values, the strength reduction factor $(\phi)$ of various systems installed by reused scaffolds can be obtained as well. For the strength reduction factor of the scaffolding system installed by reused scaffolds, it is suggested that the strength reduction factor $\phi_{(\mu-\sigma)}$ is $0.72, \phi_{(\mu-2 \sigma)}$ is 0.65 , and $\phi_{(\mu-3 \sigma)}$ is 0.58 . For the strength reduction factor of the combined system of scaffolds with wooden shores installed by reused scaffolds, it is suggested that the strength reduction factor $\phi_{(\mu-\sigma)}$ is $0.57, \phi_{(\mu-2 \sigma)}$ is 0.41 , and $\phi_{(\mu-3 \sigma)}$ is 0.25 . Depending on the on-site safety requirements, constructors can adopt an appropriate strength reduction factor $(\phi)$ to calculate the lower bound of the load-bearing capacity of different systems installed by reused scaffolds, which may serve as a reference for the strength design of reused scaffolds.

\section{Acknowledgements}

The funds for this study are provided by the Ministry of Science and Technology (MOST 109-2221-E-224-011), the National Natural Science Foundation (Grant No. U1602232), the Fundamental Research Funds for the Central Universities (Grant No. N170108029), and the Liaoning Science and Technology Project (2019JH2/10100035). The tests were completed with the assistance of Mr. Wei-Liang Lai. We would like to thank all of them.

\section{References}

[1] Yu, W.K. and Chung K.F., "Prediction on Load Carrying Capacities of Multi-storey Doortype Modular Steel Scaffolds", Steel and Composite Structures, 4, 6, 471-487, 2004a.

[2] Yu, W.K., Chung, K.F. and Chan, S.L., "Structural Instability of Multi-storey Door-type Modular Steel Scaffolds," Engineering Structures, 26, 867-881, 2004b.

[3] Pieńko, M. and Błazik-Borowa, E., "Numerical Analysis of Load-bearing Capacity of Modular Scaffolding Nodes," Engineering Structures, 48, 1-9, 2013.

[4] Jia, L., Liu, H., Chen, Z., Liu, Q. and Wen, S., "Mechanical Properties of Right-Angle Couplers in Steel Tube-Coupler Scaffolds," Journal of Constructional Steel Research, 125, 43-60, 2016.

[5] Zhao, Z. and Chen, Z., "Analysis of Door-Type Modular Steel Scaffolds Based on A Novel Numerical Method," Advanced Steel Construction, 12, 316-327, 2016.

[6] Peng, J.L., Ho, C.M., Lin, C.C. and Chen, W.F., "Load-Carrying Capacity of Single-Row Steel Scaffolds with Various Setups," Advanced Steel Construction, 11, 185-210, 2015.

[7] Peng, J.L., Wang, C.S., Wu, C.W. and Chen, W.F., "Experiment and Stability Analysis on Heavy-Duty Scaffold Systems with Top Shores," Advanced Steel Construction, 13, 293-317, 2017.

[8] Liu, H., Chen, Z., Wang, X. and Zhou, T., "Theoretical Analysis and Experimental Research on Stability Behavior of Structural Steel Tube and Coupler Falsework with X-Bracing," Advanced Steel Construction, 6, 949-962, 2010.

[9] Sevim, B., Bekiroglu, S. and Arslan, G., "Experimental Evaluation of Tie Bar Effects on Structural Behavior of Suspended Scaffolding Systems," Advanced Steel Construction, 13,
$62-77,2017$

[10] Zhang, H., Chandrangsu, T. and Rasmussen, K.J.R., "Probabilistic study of the strength of steel scaffold systems," Structural Safety, 32, 393-401, 2010.

[11] Zhang, H., Rasmussen, K.J.R. and Ellingwood, B.R., "Reliability assessment of steel scaffold shoring structure for concrete formwork," Engineering Structures, 36, 81-89, 2012.

[12] Chan, S.L. and Cho, S.H., "Second-order P- $\Delta-\delta$ Analysis and Design of Angle Trusses Allowing for Imperfections and Semi-Rigid Connections," Advanced Steel Construction, 1, 157-172, 2005.

[13] Chan, S.L., Zhou, Z.H., Chen, W.F., Peng, J.L. and Pan, A.D., "Stability Analysis of Semirigid Steel Scaffolding," Engineering Structures, 17, 568-574, 1995.

[14] Liu, S.W., Chan, J.L.Y., Bai, R. and Chan, S.L., "Curved-quartic-function Elements with End-springs in Series for Direct Analysis of Steel Frames," Steel and Composite Structures, 29, 623-633, 2018a.

[15] Liu, S.W., Ziemianc, R.D., Chen, L., Chan, S.L., "Bifurcation and large-deflection analyses of thin-walled beam-columns with non-symmetric open-sections," Thin-Walled Struct. 132, 287-301, 2018b 